\title{
Preferred Habitat vs. Efficient Market: A Test of Alternative Hypotheses
}

\author{
LLAD PHILLIPS AND JOHN PIPPENGER*
}

\begin{abstract}
Llad Phillips and John Pippenger are both Associate Professors of Economics at the University of California at Santa Barbara. The following paper is based, in part, on research done while Professor Pippenger was a visiting scholar at the Federal Reserve Bank of St. Louis in 1974. The views expressed herein are solely those of the authors and do not necessarily represent the views of the Federal Reserve Bank of St. Louis or the Federal Reserve System.
\end{abstract}

HE standard Keynesian view is that actions taken by monetary authorities affect aggregate demand by altering interest rates. Since investment and consumption presumably depend primarily on intermediate and long-term rates and central banks operate primarily in short-term markets, a transmission mechanism is needed to explain how monetary policy affects aggregate demand. Expressing long-tern rates as a distributed lag of short-term rates provides one such link.

The Preferred Habitat hypothesis of interest rate determination, as developed by Modigliani and Sutch, has received rather wide acceptance in econometric model building. The hypothesis of Modigliani and Sutch implies that long-term interest rates depend on a 16 quarter distributed lag of short-term interest rates. ${ }^{1}$ The particular form of dependence implied by the Modigliani-Sutch hypothesis is widely recognized as the dominant lag structure and this lag structure has been incorporated into several large econometric models. ${ }^{2}$

There is, however, an impressive body of empirical evidence indicating that interest rates follow a random walk; that is, movement in a given period is independent of movements in previous periods. ${ }^{3}$ This

\footnotetext{
* We would like to thank Robert Rasche and Michael Hamburger for their helpful comments and suggestions.

1Franco Modigliani and Bichard Sutch, "Innovations in Interest Rate Policy, American Economic Review (May 1966), and "Debt Management and the Tem Structure of Enterest Rates: An Empirical Analysis of Recent Experience," Joumal of Political Economy, Supplement (August 1967).

'See, for example, the Federa Reserve-MIT-Penn model and RIX2 developed by the Bank of Canada.

SSee for example, G.O. Bierwag and M.A. Grove, "A Model of the Structure of Prices of Marketable U.S. Treasury Securi-
}

evidence is consistent with the hypothesis that capital markets are efficient in the sense that prices fully reflect all available information." If capital markets are efficient and both long-term and short-term interest rates essentially perform a random walk, then long-term rates are not determined by a long distributed lag of short-term rates. If long-term interest rates do not depend on a distributed lag of short-term rates, then some important econometric models contain a potentially serious misspecification.

This conclusion would be particularly relevant for the FRB-MIT-Penn model. In this model, the transmission mechanism is essentially from monetary actions to short-term interest rates, to long-term interest rates, to aggregate expenditures, output and employment. ${ }^{5}$ Since the effect of short-term rates on longterm rates is distributed over 16 quarters, the effects

ties," Joumal of Money, Credit and Banking (Angust 1971); C.W.J. Granger and H,J,B. Rees, "Spectral Analysis of the Term Structure of Intevest Rates," Review of Economio Studies (January 1968); John Pippenger, "A Time Series Analysis of Post-Accord Interest Rates: Comment," Journal of Finance (September 1974); and Richard Roll, The Behavior of Interest Rates (New York: Basic Books, 1970). For some conflicting evidence, see Stanley Diller, The Seasonal Variation of Interest Rates, NBER Occasional Paper No. $80,1969$.

${ }_{4}^{4}$ For an excellent survey of the evidence bearing on and supporting the Efficient Market hypothesis, see Engene Fama, "Eficient Capital Markets: A Review of 'Theory and Emptrical Work,"Journal of Finance (May 1970).

$5^{4}$.... the structure of our model implies that the money supply can affect consumption, as well as every other component of demand, only through its effect on the short-term rate ..." Franco Modigliani, "Monetary Policy and Consumption: Linkages via Interest Rate and Wealth Effects in the FMP Model," Consumer Spending and Monetary Policy: The Linkages, F. Modigliani et al. (Federal Reserve Bank of Boston, $1971, \mathrm{pp}, 61-62)$. 
of monetary actions tend to be spread over a very long period of time."

The long distributed lag from short-term to longterm interest rates in the FRB-MIT-Penn model may at least partially explain why that model yields substantially different estimates from that indicated from St. Louis Federal Reserve Bank research concerning how rapidly nominal income responds to monetary policy. For example, the original Andersen-Jordan results suggest that the response of nominal income to a change in the monetary base is completed within about only four quarters. On the other hand, Modigliani describes the response of nominal income in the FRB-MIT-Penn model to a change in unborrowed reserves as follows: "The response is clearly rather slow, as the money supply responds but gradually to the increase in reserves and in tum GNP responds gradually to the change in $\mathrm{M}$. Still, by the end of the third year, the GNP multiplier seems to be close to its limiting value." 7

The results of our tests lead us to reject the Modigliani-Sutch Preferred Habitat hypothesis in favor of the Efficient Market hypothesis. This conclusion indicates that the FRB-MIT-Penn nodel embodies a misspecification of the transmission mechanism for monetary policy. In particular, our results suggest that the FRB-MIT-Penn model and other econometric models using a similar distributed lag relationship between long-term and short-term interest rates are likely to overstate the length of the lag from monetary policy to employment, income, and prices.

\section{AITERNATVE THPOTHYSES}

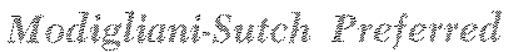

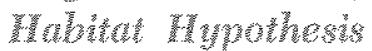

As developed by Modigliani and Sutch, the Prefered Habitat model (hereafter referred to simply as M\&S and PH, respectively) is a combination of three logically independent hypotheses. One is that market participants have a prefered habitat, that is, they tend to match the term structure of their assets and liabilities. The second is that long-term rates depend on expected future short-term rates. The third is that

\footnotetext{
6In models which incorporate monetary chanmels of influence other than, or in addition to, the cost of capital chamel, the shortening of the lags between the changes in money and the long-term interest rate would not necessarily shorten the lags between changes in money and output, prices, and employment.

7 Franco Modigliant, "Monetary Policy and Consumption," p. 54.
}

market expectations about future short-term rates contain both regressive and extrapolative elements. ${ }^{8}$

According to Modigliani and Sutch, the long-term rate $L(t)$ depends on current and past short-term rates $S(t)$ and a risk premium $F(t)$ that reflects the difference between the premium on long-term and short-term bonds generated by the Preferred Habitat.

$$
\text { (1) } \mathrm{L}(\mathrm{t})=\alpha+\beta_{0} \mathrm{~S}(\mathrm{t})+\sum_{\mathrm{i}=1}^{16} \beta_{i} \mathrm{~S}(\mathrm{t}-\mathrm{i})+\mathrm{F}(\mathrm{t})+\eta(\mathrm{t})
$$

The $\beta_{i}{ }^{*}$ s first rise and then fall as a result of extrapolative and regressive expectations. ${ }^{9}$

Since various proxies for $F(t)$ have yielded at best only weak results, this term has been omitted in practice. The operational version of the Preferred Habitat hypothesis therefore is

(2) $L(t)=\alpha^{\prime}+\beta_{0} \mathrm{~S}(\mathrm{t})+\sum_{\mathrm{i}=1}^{16} \beta_{i} \mathrm{~S}(\mathrm{t}-\mathrm{i})+\eta(\mathrm{t})$

where $F(t)$ is now absorbed into the constant $\alpha^{\prime}$ and error term $\eta^{\prime}(t)$.

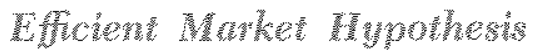

The essence of the Efficient Market hypothesis is that current interest rates fully reflect all available information. This hypothesis is in conflict with the Modigliani-Sutch postulate that market expectations contain both regressive and extrapolative elements. If capital markets are efficient and interest rates essentially perform a random walk, then market expectations contain neither regressive nor extrapolative elements. ${ }^{10}$

sAlthough the second and third hypotheses are logically separate, they are not independent empirically. As lorg as we do not have any direct measure of expected future shortterm rates, the hypothesis that current long-term rates depend on expected future short-term rates is empirically empty without a theory of how those expectations are formed.

"Modigliani and Sutch, "Inrovations in Interest Rate Policy," p. 188 .

10In a later paper, Franco Modigliani and Robert J. Shiller attempt to demonstrate that a similar model is consistent with the concept of Rational Expectations developed by J. F. Muth. Although the concepts of Rational Expectations and Efficient Markets seem to have much in common, the two approaches have developed almost entirely independently, and the relationship between them is not at all clear. See Franco Modigliani and Robert J. Shiller, "Inflation, Rational Expectations and the Term Structure of Interest Rates," Economica (February 1973). For some apparently conflicting results, see Thonas J. Sargent, "Rational Expectations and the Term Structure of Interest Rates" Jotrnal of Money, Credit and Banking (February 1972), as well as Michael J. Hamburger and Eliott Platt, "The Expectations "Hypothesis and the Efficieney of the Treasury Bil Market," Review of Economics and Statistics (May 1975 ). 
A large amount of empirical evidence indicates that there is essentially no exploitable regularity in the movement of interest rates. If that is correct, and capital markets are efficient, then current interest rates fully reflect all available information, and there should be no systematic relation between current long-term rates and lagged short-term rates. In other words, if past short-term rates contain information about future long-term rates that is not fully reflected in current long-term rates, as is the case in the PH model, then current long-term rates do not fully reflect all available information, and in this sense longterm capital markets are not efficient.

In order to provide an explicit hypothesis against which we can test the PH hypothesis of M\&S, we develop a simplified Efficient Market hypothesis (hereafter referred to as SEM), ${ }^{11}$ For simplicity, the impact of new information on capital markets is arbitrarily divided into three components: the impact of now information that is relevant primarily to the determination of short-term rates $x(t)$, the impact of new information that is relevant primarily to longterm rates $y(t)$, and the impact of new information that is relevant to both rates $z(t)$.

Under these assumptions, current long-term and short-term interest rates can be described as follows:

(3) $L(t)=L(t-1)+\lambda z(t)+y(t)$

(4) $\mathrm{S}(\mathrm{t})=\mathrm{S}(\mathrm{t}-1)+\mathrm{z}(\mathrm{t})+\mathrm{x}(\mathrm{t})$

where $x(t), y(t)$ and $z(t)$ are independent of each other and each is distributed independently over time.

This approach is based on the idea that both longterm and short-term rates essentially perform a random walk and that they are related to each other to the extent that both respond to the same information $z(t)$. This suggests we can express the relation between long-term and short-term rates as follows:

(5) $L(t)=L(t-1)+\lambda \Delta S(t)+z(t)$

where $\mathrm{u}(\mathrm{t})$ is a nonserially correlated random varia ble. However, since $\Delta S(t)$ is only a proxy for $z(t)$, and $u(t)$ [which equals $y(t)-\lambda x(t)$ ] is not independent of $\Delta S(t)$, OLS estimates of $\lambda$ are biased.

The interpretation of equation (5) is that capital markets are efficient and that both long-term and short-term rates are influenced by a common body of information. It would be more realistic to permit $x(t)$, $y(t)$, and $z(t)$ to have some structure or to postulate a whole spectrum of information and to develop a

11 This and other discussions of the Efficient Market hypothesis in this paper ignore the important role of transaction costs. model explaining the response of both long-term and short-term interest rates to each segment in that spectrum. But simplicity is a virtue, and we believe that, given the present state of knowledge, equation (5) represents a useful model for our purpose, which is to test the Preferred Habitat hypothesis of ModiglianiSutch against the Efficient Market hypothesis. ${ }^{12}$

\section{Levels $\bar{Y}$ ersus Diferences}

Over the years the results of several studies, which have used a variety of techniques, have cast doubt on the reliability of the lag structure estimated by M\&S. ${ }^{13}$ One of the most important of these is the study by Michael Hamburger and Cynthia Latta, who used a model originally suggested by John Wood. ${ }^{14}$

According to Wood, as a reasonable approximation, we can express the relation between long-term and short-term rates as follows:

(6) $L(t)=a+b S(t)+v(t)$

First-differencing this equation, which is the form in which Wood tested it, yields an equation that is apparently similar to equation (5), but differs in that the error term $\mathrm{v}(\mathrm{t})$ in the Wood model is implicitly assumed to be independent of the short-term interest rate.

M. Hamburger and $\mathrm{C}$. Latta compared the $\mathrm{PH}$ and Wood models in differences. Their paper, which anticipates much of the empirical work presented here, yields results that lead them to reject the $\mathrm{PH}$ model.

121: should be clear, however, that such a model is not the best possible altemative. A model that explicitly identified the events reflected in $x(t), y(t)$, and $z(t)$ and related them to long-term and shortuterm rates would yield a more useful explanation. The model developed by $M$. Feldstein and $G$, Chamberlain in "Multimarket Expectations and the Rate of Interest," Journal of Money, Credit, and Banking (November 1973), is one example of such at attempt.

13 See, for example, R. Dobell and T. Sargent, "The Term Structure of Interest Rates in Canada," Canadian Journal of Economics (February 1969); T. Cargill and R. Meyer, "A Spectral Approach to Estimating the Distributed Lag Relationship between Long and Short Term Interest Rates," International Economic Retiew (June 1972), and "Estimating Term Structure Phenomena from Data Aggregated over Time," Journal of Money, Credit and Banking (November 1974); V. Chetty, "Estimation of Solow's Distributed Lag Models," Econometrica (January 1971); G. Pierson, "Effect of Econornic Policy on the Term Structure of Interest Rates," Review of Economics and Statistics (February 1970); and especially M. Hamburger and C. Latta, "The Term Structure of Interest Rates," Journal of Money, Credit and Banking (February 1969). For a reply to Hamburger and Latta, see Franco Modigliani and Richard Stitch, "The Term Structure of Interest Rates: A Re-examination of the Evidence," Journal of Money, Credit and Banking (February 1969).

14Hamburger and Latta, "The Term Structure of Interest Rates." John H. Wood, "The Expectations Hypothesis, the Yield Curve, and Monetary Policy," Quarterly Journal of Economics (August 1964). 
However, as pointed out by M\&S, when the PH and Wood models are compared in levels, the PH model has greater explanatory power. ${ }^{15}$

The superiority of the PH model over the levels version of Wood's model, however, cannot be used to discriminate between the SEM and PH models. If the SEM model is essentially correct, then we would expect a distributed lag model such as the PH model to yield better results than the levels version of Wood's model. This point is demonstrated in the Appendix.

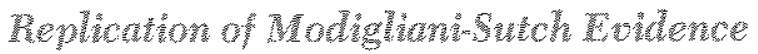

Before proceeding further, we replicate the Modigliani-Sutch evidence supporting their version of the Preferred Habitat hypothesis. They estimate their equation for two overlapping periods running from the first quarter of 1952 (I/1952) to the fourth quarter of 1961 (IV/1961) and from I/1952 to I/1966. In both periods, they use quarterly data, estimate the current short-term rate separately, and use a fourth degree Almon lag, with the 17th lag constrained to zero, to estimate the lag structure. Although they use the yield on taxable long-term government bonds to measure long-term rates in both periods, they use the yield on three-month Treasury bills calculated on a discount basis as a measure of short-term rates in the shorter period and the same rate calculated on a bond yield basis in the longer period. In the results pre sented here we use their measure of long-term rates and their bond yield measure of short-term rates. ${ }^{16}$

When we reestimate their model using equation (2) for the period running from $\mathrm{I} / 1952$ to $\mathrm{I} / 1966$, we get the same results. When we reestimate their model for the period I/1952 to IV/1961 using the bond yield measure of the short-term rate rather than the yield on a discount basis, we obtain essentially the same results. Table I shows our estimates (labeled P\&P) for both periods as well as the estimates reported by M\&S for the period I/1952 to IV/1961. Our estimates of the coefficients for lagged short-term rates with a band of plus or minus one standard error are shown in Figure I.

\footnotetext{
15Modigliani and Sutch, "The Tem Structure of Interest Rates: A Re-examination of the Evidence."

${ }_{16}$ Except for the long-term rate from $1 / 1952$ to $1 / 1953$, the data are taken from Sutch's dissertation, pp. 216-17. For the period $1 / 1952$ to $1 / 1953$, we use quarterly averages of the long-term Treasury bond yield reported in the Treasury Bulletin on a monthly basis. Sutch apparently dropped these five quarters from his later work because the maturity of the long-term bonds used to calculate the yield changed twice during this period.
}

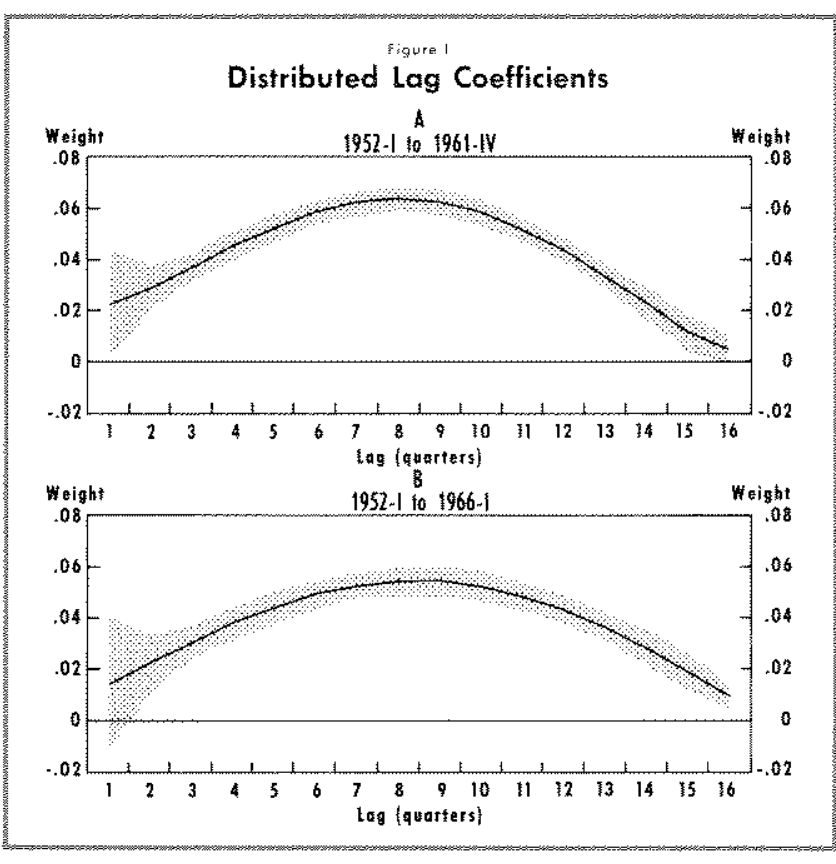

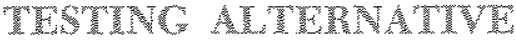

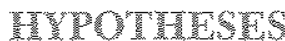

The widespread acceptance and use of the Modigliani-Sutch version of the Preferred Habitat hypothesis in econometric model building is based essentially on the results shown in Table 1 and Figure I. As compared only to the alternative hypothesis that there is no relation between long-term rates and current as well as lagged short-term rates, this evidence would lead one to accept their hypothesis.

But the null hypothesis of no relation is a straw man. In order to determine whether or not their hypothesis is the best available explanation of the determination of long-term interest rates, it should be tested against a strong alternative hypothesis. Given the very impressive amount of evidence supporting the hypothesis that organized capital markets are efficient and that both long-term and shortterm interest rates essentially perform a random walk, the SEM model developed above provides a strong alternative hypothesis.

The fundamental difference between the two hypotheses is the way capital markets respond to new information. In the SEM model formalized in equation (5), long-term and short-term rates respond fully and simultaneously to a common body of new information. As a result, all relevant information contained in past short-term rates is fully reflected in the lagged long-term rate, and the current change in the short-term rate can be viewed as a proxy for the new information that affects both rates. 
In the PH model, new information inHuences long-term rates slowly and indirectly. There the implicit hypothesis is that new information alters current shortterm rates and the change in the current short-term rates then continues to alter long-term rates over several quarters as expected future short-term rates respond over time to the new information.

Suppose, for example, that there is an unanticipated open market sale of shortterm government securities. The SEM hypothesis says that both long-term and short-term rates respond fully and simultaneously to this event when it happens. The PH hypothesis however implies that the open market operation first affects essentially only current short-term rates. Then, in response to extrapolative and regressive expectations about future shortterm rates, the long-term rate responds over time to the open market operation and the initial rise in short-term rates.

These two ways of viewing the relation between long-term and short-term interest rates are fundamentally different, and the essence of the difference concerns the nature of the information contained in lagged short-term interest rates.

The next logical step is to formulate a test that will permit us to discriminate between these two models. In order to be effective, such a test must not be prejudiced and should cast light on the essential difference between the two approaches.

One possibility, and the one M\&S insisted upon in their exchange with Hamburger and Latta, is to compare equations (2) and (6)

$$
\text { (2) } L(t)=\alpha^{\prime}+\beta_{0} S(t)+\sum_{i=1}^{16} \beta_{i} S(t-i)+n^{\prime}(t)
$$

(6) $L(t)=a+b S(t)+v(t)$

to see whether the 16 lagged short-term rates have any significant explanatory power.

Such a test does get at the heart of the issue. But, as we point out above and demonstrate in the Ap" pendix, if the SEM model is essentially correct, then this test is likely to be prejudiced in favor of the PH model.

Another alternative is to compare equation (2) and the SEM model as described by equation (5).

(5) $L(t)=L(t-1)+\lambda \Delta S(t)+L(t)$

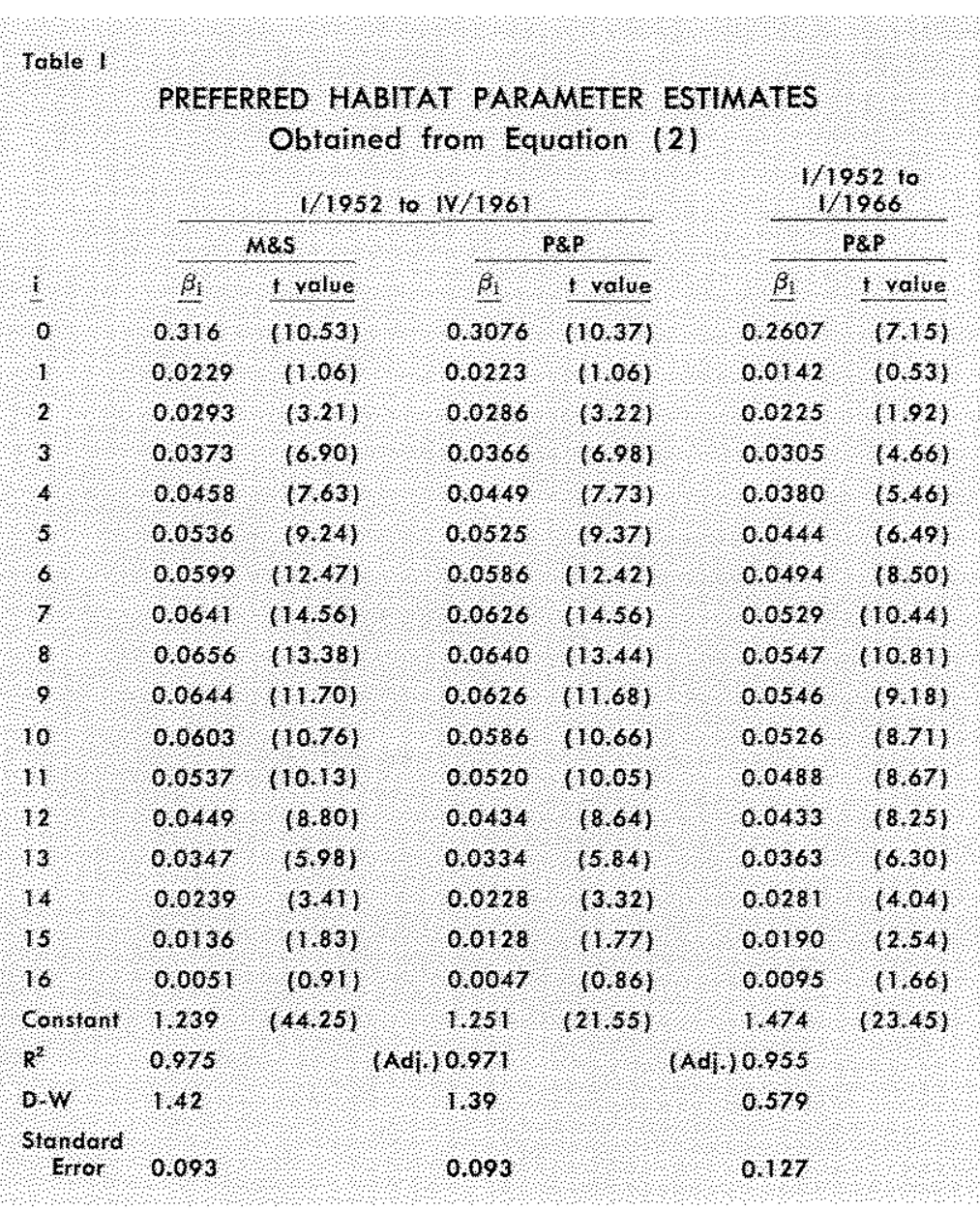

But there are two reasons for not doing this. First, the SEM model contains a lagged long-term interest rate and this could prejudice the result in favor of the SEM model. Second, such an approach does not provide a direct test of the essential difference between the two models. That is whether or not there is information in lagged short-term rates that is not fully captured by $\mathrm{L}(\mathrm{t}-\mathrm{I})$.

A third alternative, and the one we choose, is, in effect, to difference the $\mathrm{PH}$ model as expressed by equation (2) and to rewrite the differenced version as follows:

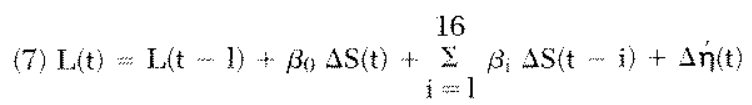

This puts the SEM and PH models on exactly the same footing and permits us to get at the essence of the difference between the two models. In addition, this approach does not appear to involve any prejudice against the PH model. For the shorter period, equation (2) yields a slightly higher adjusted $R^{2}$ than equation (7) (0.975 versus 0.962$)$, but for the 
longer period the results are reversed $(0.955$ versus $0.974) .17$

We believe equations (5) and (7) provide the basis for a fair and direct test of what is the essence of the difference between the PH and SEM models. If the market for long-term government securities is essentially efficient, the error term obtained from estimating equation (5) should be free of autocorrelation and adding lagged changes in the short-term rate should not reduce significantly the mean-squarederror. If the market is not efficient and expectations contain both regressive and extrapolative elements, then we would expect equation (7) to yield a better explanation of the long-term rate, in terms of a statistically significant smaller mean-squared-error, than equation (5).

The results from estimating equation (5) for the two overlapping periods chosen by Modigliani and Sutch are as follows:

$$
\begin{aligned}
& \text { I/1952 to IV/1961 } \\
& L(t)=0.0453+0.9949 L(t-l)+0.2218 \Delta S(t) \\
& (0.447) \quad(32.506) \quad(6.146) \\
& \widetilde{\mathrm{R}}^{2}=0.964 \quad \mathrm{SE}=0.1047 \\
& L(t)=0.0696+0.9861 \mathrm{~L}(t-1)+0.2246 \Delta S(t) \\
& (0.92) \quad(46.415) \quad(7.1346) \\
& \overline{\mathrm{R}}^{2}=0.975 \quad \text { SE }=0.0949
\end{aligned}
$$

where $t$ values are shown in parentheses.

Since the regressions contain a lagged dependent variable, the Durbin-Watson statistic is biased toward 2.0 and a more appropriate measure for serial correlation in the residuals is the $h$-statistic which has a standard normal distribution. ${ }^{18}$ The h-statistic is -0.199 for the shorter period and -0.002 for the longer period. As implied by the SEM model, there is no indication of any first order serial correlation in the residuals.

The estimated parameters of equation (7) are shown in Table II and the estimates of the coefficients for lagged changes in short-term interest rates are shown in Figure II with a band of plus or minus one standard error. Following Modigliani and Sutch we estimated

\footnotetext{
1r Since $\Delta S(t)$ and $u(t)$ are correlated in equation (5), the estimate of $\lambda$ is biased downward. This errors in variables problem can be corrected using an instrumental variables technique to estimate equations (5) and ( 7 ). Estimating equations (5) and (7) using an instrumental variables technique suggested by Denbin does not alter the conclusions drawn from the OLS estimates presented below that there is no information in the lagged $\Delta S(t)$ 's. T. Johnston, $E c o$ nometric Methods (New York: MoGraw-Hill, 1972), p. 284.

18 See Johnston, Econometric Methods, pp. 312-13.
}

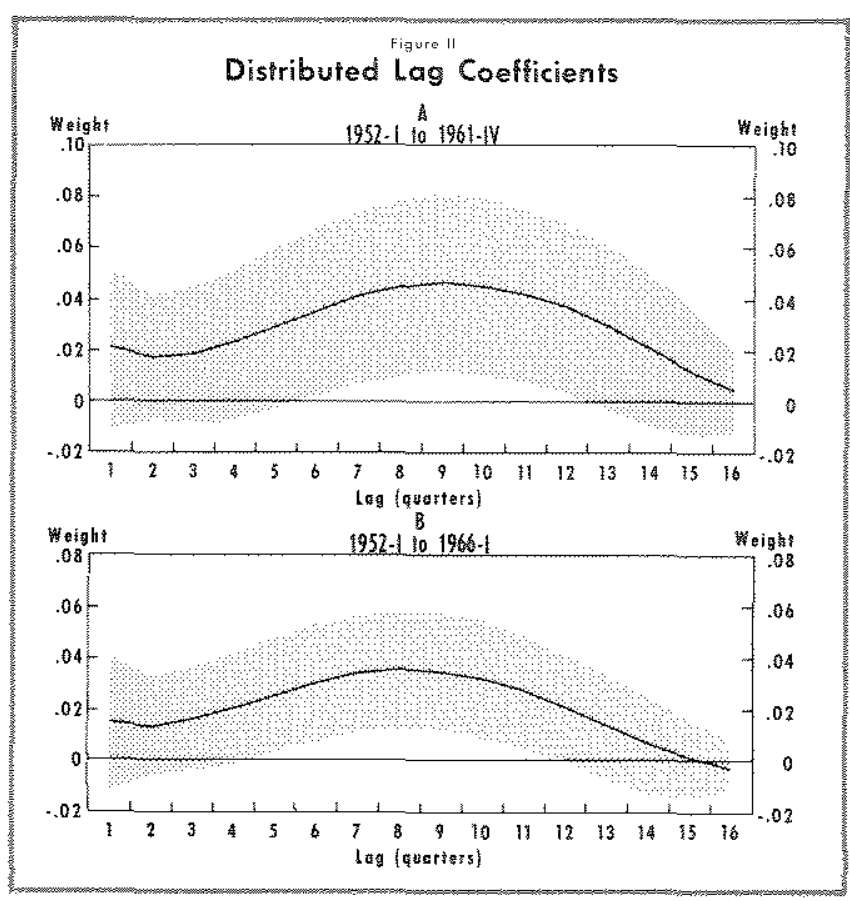

the lag structure using a fourth degree Almon lag with the 17th lag constrained to zero.

In both periods, with the exception of the first coefficient, the lag structure retains the inverted $U$ shape, but now none of the lagged coefficients are statistically significant at the five percent level. An $F$ test indicates that lagged short-term interest rates contain no information that is not already captured by the lagged long-term interest rate. For the shorter 16

period, adding $\sum_{i=1} \beta_{i} \Delta S(t-i)$ to equation (5) does not increase significantly the explained variance (an F-statistic of 0.506 ). For the longer period the same comparison yields the same result (an F-statistic of $0.77) .{ }^{19}$ This evidence does not support the claim that expectations contain regressive and extrapolative elements and that, therefore, lagged short-term interest rates contain additional information not captured by the lagged long-term interest rate.

Athough there is no evidence that lagged shortterm interest rates contain any significant information, the tendency for the inverted $U$ shape to persist suggests that there might be at least some information in

\footnotetext{
19 In order to be significant at the 5 percent level, the $F^{*}$ statistic would have to exced 2.66 for the shorter period and 2.56 for the longer period. There is the possibility that estimating the PH model as equation ( 7 ) introduces spurious autocorrelation into the residuats, thus possibly cending to bias the $F$ tests against the $P$ model. The insignificant h-statistic for the estimates of both he SEN and $2 \mathrm{P}$ models, however, suggests this is not a serious problem.
} 
Toble I

PREFERRED HABITAT PARAMETER ESTIMATES Obtained from Equation 17

\begin{tabular}{|c|c|c|c|c|c|}
\hline & \multicolumn{2}{|c|}{$1 / 1952$ to $\mathrm{V} / 1961$} & \multicolumn{3}{|c|}{$1 / 1952 \mathrm{lol} 1 / 1966$} \\
\hline 8 & $\beta$ & 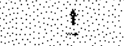 & $\beta$ & & 2 \\
\hline 0 & 0.2338 & $(5348)$ & 02385 & & $(6,604)$ \\
\hline 1 & 00209 & $106663)$ & 0,0180 & & 10.876 \\
\hline 2 & 0.0170 & 10.6891 & 00136 & & $(0.6 \% 2)$ \\
\hline 3 & 00183 & $10.681)$ & 00160 & & 07751 \\
\hline 4 & 0.0228 & 10.769 & 00204 & & $(0,923)$ \\
\hline 5 & 00289 & 10019 & 0.0256 & & $(1122)$ \\
\hline 6 & 0.0354 & 10077 & 00304 & & 113201 \\
\hline 7 & 00410 & 112061 & 0,0338 & & $(1463)$ \\
\hline 8 & 0.0449 & $(1,290)$ & 0.0354 & & 115231 \\
\hline 9 & 000466 & $11,326)$ & 0,0349 & & 11.4991 \\
\hline 10 & 0.0458 & 11,311 & 0.0321 & & $(1098)$ \\
\hline 11 & 0.0424 & 1,2331 & 0.0272 & & 112211 \\
\hline 12 & 0.0367 & 11,099 & 00208 & & $(0.966)$ \\
\hline 13 & 0.0292 & 10.9021 & 0.0135 & & 10.6561 \\
\hline 14 & 0.0206 & $(0.678)$ & 0,0064 & & $(0,333)$ \\
\hline 15 & 0.0119 & 10.4611 & 0,0007 & & 100451 \\
\hline 16 & 00046 & 10.2739 & 0,0019 & & 101841 \\
\hline 41,1 & 0.9873 & $130494)$ & 0001 & & $(4,2291$ \\
\hline Consfont & 0.0497 & $(0.473)$ & 0.0705 & & 109111 \\
\hline $\mathrm{R}^{2}$ & & & & 0.974 & \\
\hline 1 & & & & 0,558 & \\
\hline Standord & & & & 0.0957 & \\
\hline DF & & & & 50 & \\
\hline
\end{tabular}

models is based primarily on three factors. They are as follows. First is the ability of the model to explain the behavior of longterm interest rates over the sample period in the sense of a high $\mathrm{R}^{2}$. Second is the significance of the lag structure. Many of the t-statistics are over 5 . Third, the estimated lag coefficients take the form of a smooth inverted U, which Modigliani and Sutch interpret as being consistent with extrapolative and regressive expectations.

With respect to the smooth inverted $U$, our results suggest that this is due to the Almon techique, which forces the estimates to fit a smooth curve, rather than the result of extrapolative and regressive expectations.

As for the significance of the lagged shortterm rates that M\&S found in their $P H$ formulation given by equation (2), the SEM model proposed here suggests that such statistical significance need not be interpreted as evidence of extrapolative and regressive expectations. The SEM model, as presented in the text and amplified in the Appendix, explains how adding lagged shortterm rates can improve the fit obtained from

the distributed lag. Alternatively, the smooth inverted $U$ may be the result of using a low degree Almon polynomial rather than the result of extrapolative and regressive expectations.

In order to obtain some evidence on this point, we estimate the lag structure in equation (7) using ordinary least squares. Since changes in Treasury bill rates essentially are uncorrelated, multicollinearity is not a problem and, under the assumptions of the PH model, OLS regression provides an unbiased estimate of the parameters. Regression restults using ordinary least squares are shown in Table III. Figure III shows the estimates of the coefficients for lagged changes in short-term rates with a band of plus or minus one standard error. In neither period is there a smooth inverted $U$. This result suggests that the smooth inverted $U$ is the result of using the Almon lag.

\section{CONGLUSION}

The acceptance of the Preferred Habitat model and its widespread use in econometric 


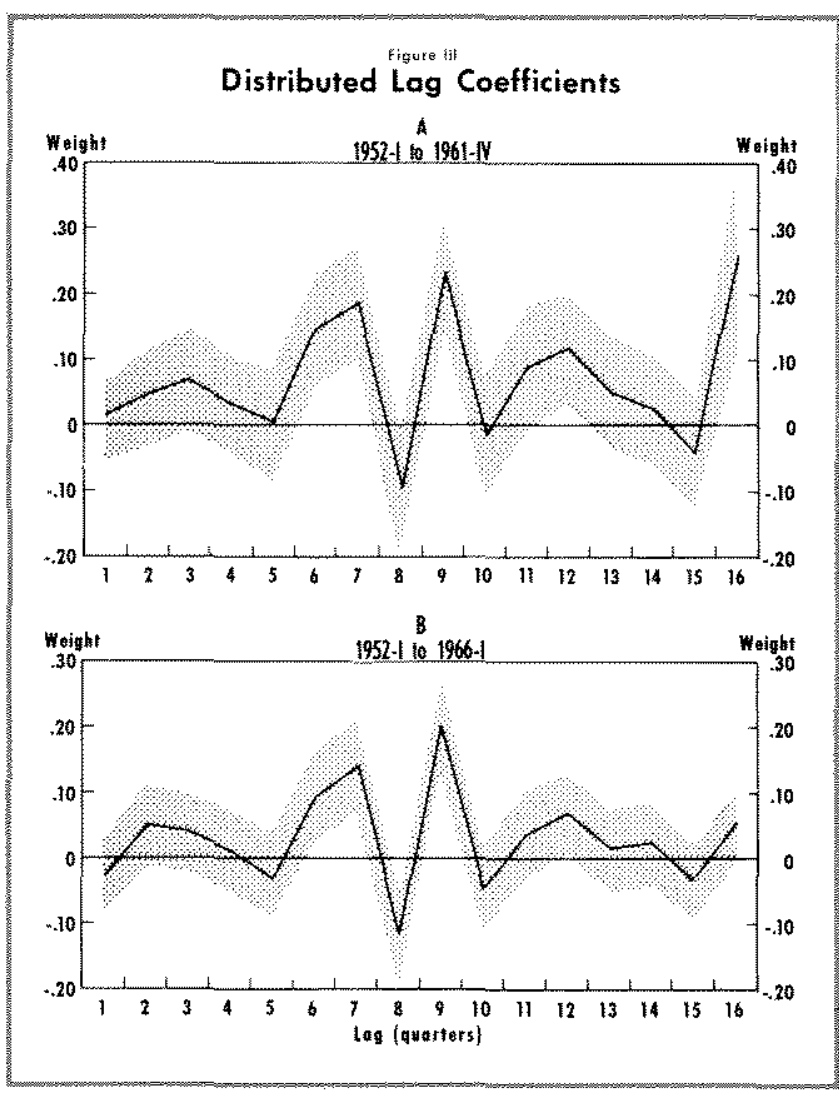

regressing the current long-term rate on the current short-term rate even though long-term rates do not depend on lagged short-term rates.

With respect to the high $R^{2}$ obtained by M\&S, we find that in order to explain the current long-term interest rate, it is sufficient to use the long-term rate lagged one quarter and the current change in the short-term rate. The addition of lagged changes in short-term rates does not add significantly to the explanation of the current long-term rate. This finding is consistent with the SEM model, but inconsistent with the PH model as specified by M\&S. This result, which is part of a large and growing body of evidence that conflicts with the term structure model suggested by Modigliani and Sutch, leads us to reject the Preferred Habitat model in favor of the Simplified Efficient Market hypothesis.

Although a comparison of the two models leads us to reject the $\mathrm{PH}$ model, we recognize that the SEM model is a naive hypothesis that can and should be improved upon. We are trying to extend the SEM model and we hope that in the process we will be able to contribute to a better understanding of the relation between short-term and long-term interest rates.

\section{APIPNDII}

We can demonstrate as follows why we would expect the PH model to yield better results than the levels version of the Wood's model. Equations (3) and (4) can be solved as follows to express $L(t)$ and $S(t)$ in levels.

$$
\begin{aligned}
& \text { (I) } L(t)=\prod_{i=0}^{\infty} z(t-i)+\sum_{i=0}^{\infty} y(t-i) \\
& \text { (II) } S(t)=\sum_{i=0}^{\infty} z(t-i)+\sum_{i=0}^{\infty} x(t-i)
\end{aligned}
$$

Using equations (I) and (II) to express the relation between the long-term and short-tern rate in levels yields the following.

(III) $L(t)=\lambda S(t)+\sum_{i=0}^{\infty}[y(t-i)-\lambda x(t-i)]$
Comparing equations (III) and (6) we see that if the SEM model is correct, the error term $v(t)$ in the Wood model is a randon walk, i,e., a sum over time of uncor. related random variables and, therefore, highly autocorrelated. As a result, we would expect that the estimation of the Wood model, i.e., equation (6), using ordinary least squares would not do as well as alternative specifcations which use proxies to explain some of the structure in the error term $v(t)$. One proxy, of course, is lagged $S(t)$, which like $v(t)$, has strong positive autocorrelation.

In addition we note from equation (4) that $S(t)$ depends on $x(t)$. Since $v(t)$ is composed partly of lagged $x(t)^{\prime}$ s, the addition to equation $(6)^{\prime}$ of a distributed lag on $S(t)$ should do better than the Wood model described by equation (6). That is, 
(IV) $L(t)=a+b S(i)+\sum_{i=1}^{n} b_{i} S(t-i)+v^{\prime}(t)$

should "explain" some of the residual variance in the Wood model.

Under these conditions, however, such an improvement does not imply that current changes in $\mathrm{L}(\mathrm{t})$ depend in any way on the past behavior of $S(t)$. In other words, the SEM model explains why a distributed lag on $S(t)$ could contribute to the explanation of $L(t)$ even though changes in long-term and short-term rates are only contempraneously correlated.

If the SEM model is essentially correct, then the relation between $S(t)$ and $L(t)$ is symmetric. We can derive equation (V) from equations (I) and (II)

(V) $S(t)=a^{\prime}+b^{\prime} L(t)+w(t)$

where

$w(t)=\sum_{i=0}^{\infty}\left[x(t-i)-\frac{1}{\lambda} y(t-i)\right]$

and $w(t)$, therefore, has the same properties as $v(t)$ in equation (6). That is, $w(t)$ should be roughly a random walk and $w(t)$ should not be independent of $L(t)$. If our argument about the effect of adding lagged short-term rates to equation $(6)$ is correct, then we should obtain similar results by adding lagged long-term rates to equation (V). That is,

(VI) $\mathrm{S}(\mathrm{t})=\mathrm{a}^{\prime}+\mathrm{b}^{\prime} \mathrm{L}(\mathrm{t})+\sum_{i=1}^{\mathrm{n}} \mathrm{b}_{i}^{\prime} \mathrm{L}(\mathrm{t}-\mathrm{i})+\mathrm{w}^{\prime}(\mathrm{t})$

should "explain" some of the residual variance in equation $(\mathrm{V})$.

When we estimate equation (V) for the two periods used by M\&S, we get the following results:

1952-I to $1961-\mathrm{IV}$

$$
\begin{aligned}
& \mathrm{S}(\mathrm{t})=-\begin{array}{c}
-1.5934+1.1798 \mathrm{~L}(t) \\
(2.92) \quad(7.24)
\end{array} \\
& \mathrm{R}^{2}=0.579 \text { DW }=0.4300 \quad \mathrm{SE}=0.5654
\end{aligned}
$$

1952-I to 1966-I

$$
\begin{aligned}
& \mathrm{S}(\mathrm{t})=-\underset{(5.07)}{2.1021}+1.3451 \mathrm{~L}(\mathrm{t}) \\
& \mathrm{R}^{2}=0.7121 \quad \mathrm{DW}=0.3572 \quad \mathrm{SE}=0.5195
\end{aligned}
$$

where $t$ values are shown in parentheses.

If we follow M\&S and use a fourth degree polynomial with a tail constraint to estimate equation (VI) where $\mathrm{n}$ equals 17 , we obtain the results shown in Table IV. As expected, the lagged long-term rates appear to add significantly to the explanation of the current short-term rate.

It should be pointed out that we did not search to obtain an optimum fit. We simply reversed the roles of long-term and short-term rates and then followed exactly the procedure used by M\&S. The results shown in Table IV strongly support our claim that the significant lag structure obtained by M\&S is not the result of extrapoliative and regressive expectations.

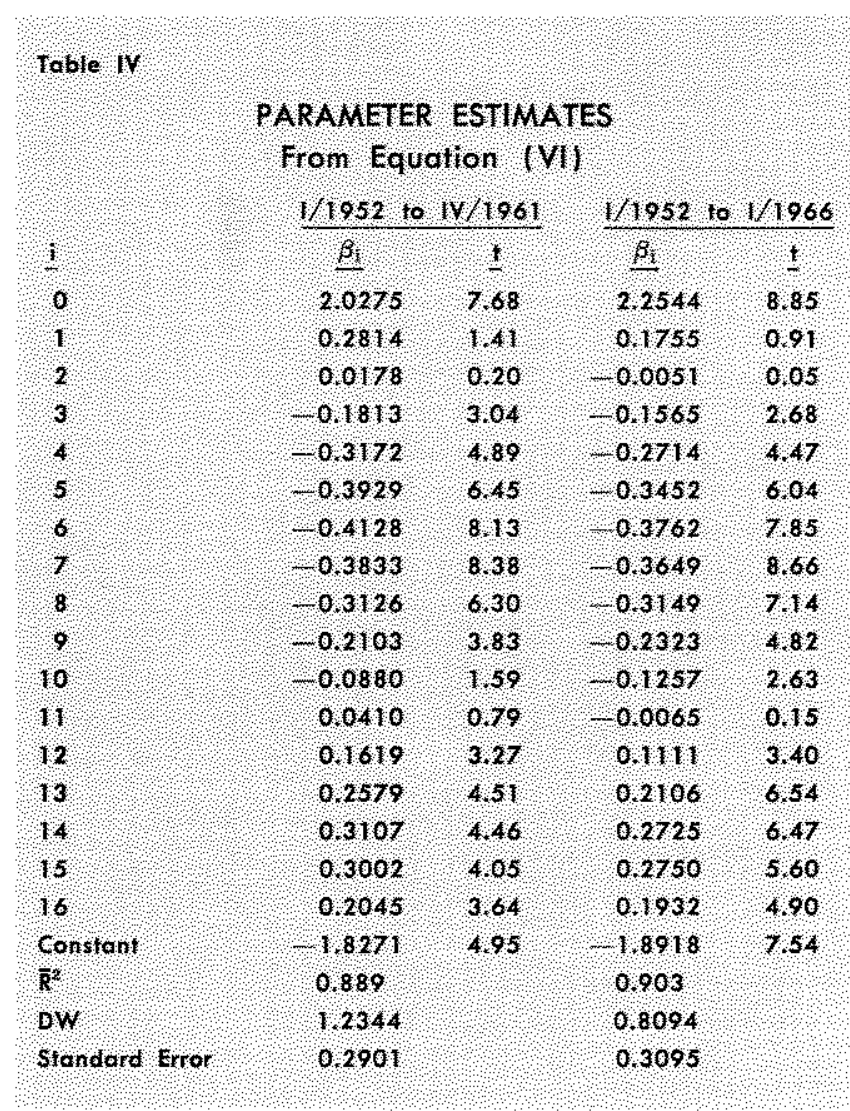

But equation (IV) is not the only possible modification of the Wood model which would account for some of the variance in the error term $v(t)$. Equation (4) of the SEM model implies that $\Delta S(t)$ and $x(t)$ are correlated. Thus a distributed lag on $\Delta S(t)$ should explain some of the variance in the error term $v(t)$ in equation (6). That is, (VII) $L(t)=a+b S(t)+\sum_{i=1}^{n} b_{i} \Delta S(t-i)+v^{\prime \prime}(t)$

also should do better than the Wood model.

The SEM model, however, implies that the best way to capture the error variance in Wood's model is not to restrict the proxies for $\sum_{i=0}^{\infty} x(t-i)$ and the structure in $v(t)$ to $S(t)$ or $\Delta S(t)$, but to use $L(t-1)$ and $S(t-1)$.

From equation (III) we see that the error $v(t)$ in the Wood model can be expressed as follows:

(VIII) $v(t)=\sum_{i=0}^{\infty} y(t-i) \cdots \lambda \sum_{i=0}^{\infty} x(t-i)=L(t)-\lambda S(t)$

But equation (VIII) implies that

(IX) $L(t-1) \cdots \lambda S(t-1)=\sum_{i=1}^{\infty} y(t-i) \cdots \lambda \sum_{i=1}^{\infty} x(t-i)$

As a result, we can use $(L(t-1)-\lambda S(t-1))$ to capture all of $v(t)$ except for the two terms $y(t)$ and $\lambda x(t)$. When we do this by combining equations (III) and (IX), we return full circle to equation (5) where the error term is orthogonal. 